\title{
Color preference of Anastrepha obliqua (Diptera, Tephritidae)
}

\author{
Guillermo López-Guillén, Armando Virgen \& Julio C. Rojas
}

Departamento de Entomología Tropical, El Colegio de la Frontera Sur, Tapachula, Chiapas, CP 30700, Mexico. glopez@ecosur.mx

\begin{abstract}
Color preference of Anastrepha obliqua (Macquart) (Diptera, Tephritidae). The color preference of A. obliqua was evaluated in two-choice tests. The results showed that both sexes were attracted to wavelengths ranging from $340 \mathrm{~nm}$ to $670 \mathrm{~nm}$, although the broad major peak of attraction occurred between 380 and $570 \mathrm{~nm}$.
\end{abstract}

KEYWORDS. Behavior; fruit fly; olfactometer.

RESUMO. Preferência de cor por Anastrepha obliqua (Macquart) (Diptera, Tephritidae). A preferência de cor por A. obliqua foi avaliada em testes de dupla escolha. Os resultados mostraram que ambos os sexos foram atraídos aos comprimentos de onda que variam de $340 \mathrm{~nm}$ a de $670 \mathrm{~nm}$, embora o principal pico da atração de A. obliqua tenha ocorrido entre 380 e $570 \mathrm{~nm}$.

PALAVRAS-CHAVE. Comportamento; mosca-das-frutas; olfatômetro.

The West Indian fruit fly, Anastrepha obliqua (Macquart), is considered a pest of several economically important fruit crops (Enkerlin et al. 1989). The most common host of this species is the hogplum fruit (Spondias spp.), although its principal economic damage occurs in mango (Mangifera indica L.), sapodilla (Achras zapota L.) and guava (Psidium guajava L.) (Hernández-Ortiz 1992). This fruit fly has been recorded from the USA (Florida and Texas) to South America, including the Caribbean Islands (Hernández-Ortiz \& Aluja 1993).

Tephritid fruit flies use visual and chemical cues to seek and assess habitat, food, mating sites and ovipositional resources (Economopoulos 1989). Several studies have examined the response of tephritids to models of different shape, size and color (Katsoyannos 1989; Epsky \& Heath 1998). The results obtained by these studies have allowed the design of more effective traps for monitoring tephritid populations. In the case of A. obliqua little is known about its visual ecology (López-Guillén 2008). The aim of this work was to determine the preference of A. obliqua to different wavelengths of light under laboratory conditions. The information obtained could eventually allow the improvement of traps used for monitoring A. obliqua.

Fruit flies used in this study were obtained as pupae from the Moscafrut mass-rearing facility in Metapa de Domínguez, Chiapas, Mexico. The insects were sexed after adult emergence and maintained as reported by López-Guillén (2008). The color preference of 8 to 12-d-old males and females was evaluated in two-choice tests. The flies were exposed to two wavelengths of equal quanta flux of 0.1 ì and $2.3 \mathrm{mV}$ measured with microammeter (Master ${ }^{\circledR}$ Mod. MAS830L) in a T-tube olfactometer similar to that described by Brown et al. (1998). The olfactometer consisted of a T-shaped glass tube with an internal diameter of $20 \mathrm{~mm}$. The main arm of the apparatus was $300 \mathrm{~mm}$ long with a side arm $50 \mathrm{~mm}$ long placed at the centre. The main arm was divided into three equal $100 \mathrm{~mm}$ sectors and secured horizontally to a wooden base. Bandpass filters of 20 $\mathrm{nm}$ (Andover Corp., $\mathrm{NH}$ ) were placed at the ends of the main $\mathrm{arm}$. The light was provided by two illuminators with optical fiber (Fiber-Lite PL-750, Dolan-Jenner Industries, MA), one at each end, equipped with a halogen lamp of $150 \mathrm{~W}$ (Osram, Mexico City). The bioassays were performed in a darkroom so that the only sources of light consisted of the two light sources at each end of the main arm.

During each bioassay, one end of the chamber was illuminated with a control wavelength $(570 \mathrm{~nm})$, to which most insects possess photoreceptors (Briscoe \& Chittka 2001), and the other by one of 14 wavelengths between $340-670 \mathrm{~nm}$, chosen in random order. A fly chosen at random was introduced into the side arm of the olfactometer, which was then sealed with hyaline plastic film (Great Value, Mexico City). Then, the lights were turned off and the olfactometer was covered with a black box. After 5 min, the position of the fly inside the olfactometer was recorded. The position of the filters was reversed after five replicates. The olfactometer was washed out periodically with water and acetone, and dried in an oven at $100^{\circ} \mathrm{C}$ for at least $30 \mathrm{~min}$ to remove any traces left by the insects. In total, 10 replications per sex were performed for each wavelength. The flies were used only once. During the experiments, the temperature and relative humidity in the bioassay room were maintained at $25 \pm 2^{\circ} \mathrm{C}$ and $60 \pm 10 \% \mathrm{RH}$, respectively. 
The data regarding the preference of female and male $A$. obliqua was analyzed using an analysis of variance (ANOVA). Fly response to the different wavelengths and control wavelength were analyzed using a log likelihood ratio test ( $G$ test) for goodness-of-fit with Williams' correction.

The tests showed that there was no sexual difference in the response of A. obliqua to the different wavelengths tested $(F=0.0002 ; d f=1,278 ; P=0.989)($ Fig. 1). Both sexes were attracted to wavelengths between 380 and $570 \mathrm{~nm}$. In all cases, the attraction was different between wavelength treatment and wavelength control $(P<0.05)$ (Table I), with the exception of the $540 \mathrm{~nm}$ wavelength $(P>0.05)$. In contrast, flies were not attracted to wavelengths ranging between 340 and $370 \mathrm{~nm}$, and from 590 to $670 \mathrm{~nm}$, in these cases the response was lower than the wavelength control $(P<0.05)$ (Table I and Fig. 1 ).

The relative attraction of $A$. obliqua females and males was similar, ranging from $340 \mathrm{~nm}$ and $670 \mathrm{~nm}$. The broad major peak of A. obliqua attraction occurred between 380 and 570 $\mathrm{nm}$, this range corresponds to ultraviolet (UV) and visible spectrum light. Within the visible spectrum, the wavelengths preferred by A. obliqua correspond to violet, blue, green and yellow. Similar tendencies have been observed in Rhagoletis pomonella (Walsh) to monochromatic light stimuli from ultraviolet $(350 \mathrm{~nm})$ to red $(675 \mathrm{~nm})$ wavelengths, with the peak of response occurring from 380 to $570 \mathrm{~nm}$ (blue-green to yellow), with a plateau from 600 to $625 \mathrm{~nm}$ (orange-red) (Agee 1985). In Bactrocera dorsalis (Hendel), the plateau response occurred between 350 and $490 \mathrm{~nm}$ (Wu et al. 2007). Laboratory and field studies have shown that A. ludens is attracted to yellow and green (Robacker et al. 1990; Robacker 1992), whereas A. suspensa showed a preference for orange (580 $590 \mathrm{~nm}$ ) (Greany et al. 1978).

Both sexes of A. obliqua were attracted to UV wavelength.

Table I. Results of G test testing the response of Anastrepha obliqua to different wavelengths of light under laboratory conditions.

\begin{tabular}{cllllll}
\hline & \multicolumn{2}{c}{ Females } & & \multicolumn{2}{c}{ Males } \\
\cline { 2 - 3 } \cline { 5 - 6 } $\mathrm{E}$ & $G$ & $P$ & & $G$ & $P$ \\
\hline 340 & 7.01 & 0.008 & & 7.01 & 0.008 \\
350 & 12.27 & 0.000 & & 7.01 & 0.008 \\
370 & 12.27 & 0.000 & & 12.27 & 0.000 \\
380 & 7.01 & $0.008^{*}$ & & 7.01 & $0.008^{*}$ \\
400 & 12.27 & $0.000^{*}$ & & 12.27 & $0.000^{*}$ \\
420 & 12.27 & $0.000^{*}$ & & 7.01 & $0.008^{*}$ \\
460 & 7.01 & $0.008^{*}$ & & 7.01 & $0.008^{*}$ \\
490 & 12.27 & $0.000^{*}$ & & 7.01 & $0.008^{*}$ \\
520 & 3.67 & $0.008^{*}$ & & 7.01 & $0.008^{*}$ \\
540 & 3.67 & $0.055 \mathrm{NS}$ & & 3.67 & $0.055 \mathrm{NS}$ \\
590 & 12.27 & 0.000 & & 12.27 & 0.000 \\
640 & 12.27 & 0.000 & & 12.27 & 0.000 \\
650 & 12.27 & 0.000 & & 12.27 & 0.000 \\
670 & 12.27 & 0.000 & & 12.27 & 0.000 \\
\hline
\end{tabular}

Ten flies tested per replication. Asterisk indicates values are significantly higher than the control ( $G$-test, $d f=1, P<0.05)$. NS indicates nonsignificant differences $(P>0.05)$. Values without asterisk and NS indicate that the control was higher than the treatment $(P<0.05)$.

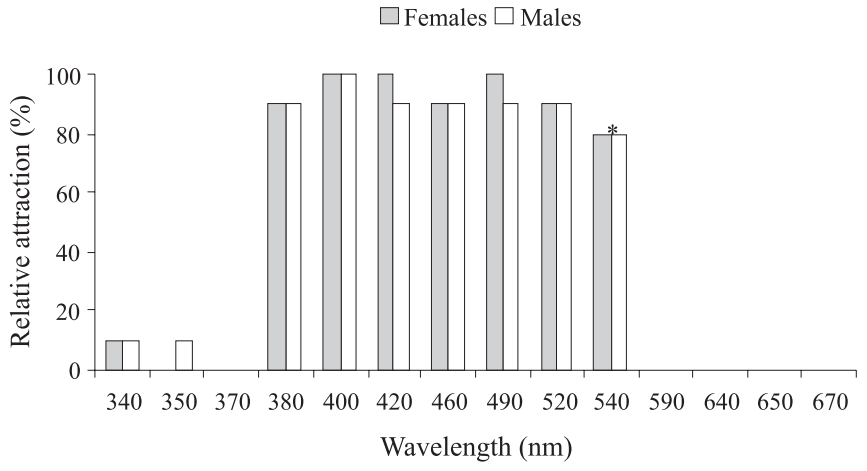

Fig. 1. Behavioral response of Anastrepha obliqua to different wavelength of light under laboratory conditions. The values indicated with $*$ are similar to the control $(P>0.05)$.

A similar situation has been reported for other tephritids such as R. pomonella and B. dorsalis (Agee 1985; Wu et al. 2007). In nature the surface wax of several fruits reflects UV light (Willson \& Whelan, 1989), which may partly explain the attraction of tephritids to host fruits (Drew et al. 2003). From a practical point of view our results suggest that the addition of the UV component on traps could improve their efficiency in capturing A. obliqua, such as has been demonstrated with $B$. dorsalis, Bactrocera tryoni (Froggatt) and Bactrocera cacuminata (Hering) (Drew et al. 2003; Wu et al. 2007).

In conclusion, the results of this study demonstrated that both sexes of $A$. obliqua were similarly attracted to wavelengths ranging from $340 \mathrm{~nm}$ to $670 \mathrm{~nm}$, although the broad major peak of attraction occurred between 380 and $570 \mathrm{~nm}$.

Acknowledgments. This work was supported by CONACyT through a grant (integral support for doctoral thesis) and a scholarship to G.L.G.

\section{REFERENCES}

Agee, H. R. 1985. Spectral response of the compound eye of the wild and laboratory-reared apple maggot fly, Rhagoletis pomonella. Journal of Agricultural Entomology 2: 147-154.

Briscoe, A. D. \& L. Chittka. 2001. The evolution of color vision in insects. Annual Review of Entomology 46: 471-510.

Brown, P. E; C. P. Frank; H. L. Groves \& M. Anderson. 1998. Spectral sensitivity and visual conditioning in the parasitoid wasp Trybliographa rapae (Hymenoptera: Cynipidae). Bulletin of Entomological Research 88: 239-245.

Drew R. A. I.; R. J. Prokopy \& M. C. Romig. 2003. Attraction of fruit flies of the genus Bactrocera to colored mimics of host fruit Entomologia Experimentalis et Applicata 107: 39-45.

Economopoulos, A. P. 1989. Use of traps based on color and/or shape. In: Robinson, A. S.; Hooper, G. (ed.). Fruit Flies: Their Biology, Natural Enemies and Control. Volume 3B. Elsevier Science Publishers, Amsterdam, The Netherlands. 447 p.

Enkerlin, D.; L. García R. \& F. López M. 1989. Pest status: Mexico, Central and South America. In: Robinson, A. S.; Hooper, G. (ed.) Fruit Flies: Their Biology, Natural Enemies and Control. Volume 3A. Elsevier Science Publishers, Amsterdam, The Netherlands. 372 p.

Epsky, N. D. \& R. R. Heath. 1998. Exploiting the interactions of chemical and visual cues in behavioral control measures for pest tephritid fruit flies. Florida Entomologist 81: 273-282.

Greany, P. D.; A. K. Burditt Jr.; H. R. Agee \& D. L. Chambers. 1978. 
Increasing effectiveness of visual traps for the Caribbean fruit fly, Anastrepha suspensa (Diptera: Tephritidae), by use of fluorescent colors. Entomologia Experimentalis et Applicata 23: 20-25.

Hernández-Ortiz, V. 1992. El género Anastrepha Schiner en México (Diptera: Tephritidae): Taxonomía, distribución y plantas hospederas. Instituto de Ecología, A. C. y Sociedad Mexicana de Entomología. Publ. No. 33. Xalapa, Veracruz, México. 162 p.

Hernández-Ortiz, V. \& M. Aluja. 1993. Listado de especies del género neotropical Anastrepha (Diptera: Tephritidae) con notas sobre su distribución y plantas hospederas. Folia Entomologica Mexicana 88: 89-105.

Katsoyannos, B. I. 1989. Response to shape, size and color. In: Robinson, A. S.; Hooper, G. (ed.). Fruit Flies: Their Biology, Natural Enemies and Control. Volume 3A. Elsevier Science Publishers, Amsterdam, The Netherlands. 372 p.

López-Guillén, G. 2008. Estímulos visuales y químicos como potenciales atrayentes de Anastrepha obliqua (Macquart) (Diptera: Tephritidae). Ph. D. dissertation, Colegio de Postgraduados, Texcoco, Mexico. 118 p.

Robacker, D. C. 1992. Effects of shape and size of colored traps on attractiveness to irradiated, laboratory-strain Mexican fruit flies (Diptera: Tephritidae). Florida Entomologist 75: 230-240.

Robacker, D. C.; D. S. Moreno \& D. A. Wolfenbarger. 1990. Effects of trap color, height, and placement around trees on capture of Mexican fruit flies (Diptera: Tephritidae). Journal of Economic Entomology 83: 412-419.

Willson, M. F. \& C. J. Whelan. 1989. Ultraviolet reflectance of fruits of vertebrate-dispersed plants. Oikos 55: 341-348.

Wu, W. Y., Y. P. Chen \& E. C. Yang. 2007. Chromatic cues to trap the oriental fruit, Bactrocera dorsalis. Journal of Insect Physiology 53: $509-516$ 